\title{
ESTUDO DAS CONDIÇÕES GERAIS DA PONTE PIQUET CARNEIRO NO MUNICÍPIO DE ICÓ/CE
}

\author{
FRANCISCA SARA. MELO \\ Aluna de Graduação \\ Universidade Federal Rural do Semiárido \\ Rio Grande do Norte, Brasil \\ Saravieira123vieirasara@hotmail.com \\ WESLEY ARTUR. SANTOS \\ Aluno de Graduação \\ Universidade Federal Rural do Semiárido \\ Rio Grande do Norte, Brasil \\ Wesleyartur-tw@hotmail.com
}

\author{
MARCILENE . NÓBREGA \\ Professora Dra. do Magistério Superior \\ Universidade Federal Rural do Semiárido \\ Rio Grande do Norte, Brasil \\ marcilenenobrega@ufersa.edu.br
}

\section{RESUMO}

As pontes são estruturas que surgiram quando as populações tiveram que interconectar pontos distintos por estruturas seguras. Embora não seja a única opção, as pontes de concreto armado são utilizadas na construção civil por possuir boa resistência à compressão e terem um tempo de vida útil considerável. Entretanto, para manter sua durabilidade a mesma deve ser submetida à manutenção e acompanhamento de suas condições gerais. Como o acompanhamento é algo essencial, o objetivo deste estudo foi realizar um levantamento das condições gerais da Ponte Piquet Carneiro localizada no município de Icó/CE. Neste estudo foi realizada a verificação da incidência de possíveis manifestações patológicas. Além disso, para a etapa de levantamento das condições gerais foram efetuadas visitas "in loco" com o auxílio de registros fotográficos. Durante as visitas, foi possível observar que a ponte se encontra deteriorada, apresentando manifestações patológicas principalmente na superestrutura e mesoestrutura do tipo fissuras, trincas, manchas, desplacamento, corrosão das armaduras e eflorescência. No entanto, considerando o seu tempo de uso (aproximadamente 80 anos) e que a mesma nunca passou por uma manutenção mais rigorosa, o estado geral da ponte pode ser considerado satisfatório.

Palavras-chave: Manifestações Patológicas. Concreto Armado. Pontes.

\begin{abstract}
Bridges are structures that emerged as populations had to interconnect distinct points by secure structures. Although not the only option, reinforced concrete bridges is used in civil construction due to their high compressive strength and its useful life time. However, to maintain its durability it must be subjected to the maintenance and monitoring of its general conditions. Because monitoring is essential, the aim of this study was to make a survey of the general conditions of the Piquet Carneiro Bridge located in the city of Icó/CE. In this study, the incidence of possible pathological manifestations was verified. In addition, for the general conditions survey stage, on-site visits were made with photographic records. During the visits, it was possible to observe that the bridge is deteriorated, presenting pathological manifestations mainly in the superstructure and mesostructure of the type fissures, cracks, stains, reinforcement corrosion and efflorescence. However, considering its lifetime (approximately 80 years) and the fact that it has never experienced rigorous maintenance, the general condition of the bridge can be considered satisfactory.
\end{abstract}

Keywords: Pathological Manifestations. reinforced concrete. Bridges. 


\section{INTRODUÇÃO}

No território brasileiro o transporte de mercadorias na maior parte das vezes ocorre através de rodovias. Em função disso as vias rodoviárias têm valor importante na economia nacional. Nesse contexto, as pontes rodoviárias têm sua função quando interligam os trechos e regiões exigem um olhar singular, desde a concepção do projeto até sua fase de utilização.

As pontes são estruturas que dão continuidade a uma via de comunicabilidade qualquer que compreende um fluxo de veículos e visam a transposição de obstáculos naturais ou já criados pelo homem que podem ser: rios, braços de mar, vales profundos, outras vias entre outros. Quando esse obstáculo for um rio considera-se ponte e quando este por sua vez for um vale ou outra via é denominado viaduto. Levando em consideração os aspectos estruturais, as pontes podem ser subdivididas nos seguintes elementos: infraestrutura, mesoestrutura e superestrutura e seus principais requisitos são funcionalidade, segurança, estética, economia e durabilidade. (MARCHETTI, 2017).

As pontes se classificam, de acordo com os materiais utilizados na sua construção. Cabe destacar que cada tipo de ponte possui suas particularidades, pois cada material tem suas propriedades características. Por consequência têm-se na ordem temporal, segundo Leonhardt (2013), os seguintes tipos de pontes: pontes de madeira, de pedra, metálicas, de concreto armado, de concreto protendido. A partir de então as pontes vêm ganhando um grande espaço na construção civil e o seu desenvolvimento quanto à durabilidade aumentando.

As estruturas de forma geral são afetadas ao longo do tempo com os efeitos das ações externas como: frequentes chuvas, incidência de raios solares, a exposição à variação de temperatura, presença de umidade e/ou com o envelhecimento natural. Estas ações podem provocar danos como fissuras, corrosões de armaduras, carbonatação e lixiviação que são algumas manifestações patológicas mais frequentes, que resultam na fragilidade da obra.

O concreto armado, embora seja conhecido pela sua durabilidade, é um material pouco resistente à tração por isso as trincas e fissuras são tão comuns nesse tipo de estrutura (BERTOLINI, 2014). Além do mais as manifestações patologias nas edificações são os principais problemas que comprometem a vida útil das construções. Pode-se notar segundo Vitorio (2006) que ao longo do tempo há escassez em programas, voltados para manutenção e conservação de pontes e viadutos, que são sobrecarregadas diariamente pelo grande fluxo de veículos de pequeno e grande porte que transitam diariamente sobre ambas, acarretando sérios problemas para o sistema rodoviário, assim como graves manifestações patológicas (VITÓRIO, 2006).

A Ponte Piquet Carneiro tem importância significativa para a região de Icó no Estado do Ceará. A mesma foi idealizada para facilitar o fluxo dos veículos automotores de pequeno e grande porte. Quando essas estruturas sofrem danos com o decorrer do tempo e não é realizada manutenção, esses danos podem colocar em risco a toda a população que trafega pela mesma. A ênfase na identificação e tratamento desses problemas, também é viável para com órgãos públicos, visto que o custo por parte de uma manutenção de uma obra desse porte é mais viável e em conta do que o início de uma nova obra dessa ou uma restauração maior.

O objetivo principal deste trabalho foi realizar um levantamento das condições gerais Ponte Piquet Carneiro sobre o Rio Salgado e a possibilidade de incidência de manifestações patológicas. Como objetivo específico procurou-se realizar o levantamento das possíveis manifestações patológicas presentes na ponte e discutir as possíveis causas da ocorrência das manifestações.

\section{FUNDAMENTAÇÃO TEÓRICA}

\subsection{Considerações gerais sobre pontes}

As pontes surgiram a partir de observações, quando os troncos, árvores e até mesmo grandes rochas caiam sobre percursos d'agua e formavam um elo, desta maneira foram surgindo ideias, copiadas desse fenômeno, resultando diferentes modelos entre os mais variados tipos, como de pedra, corda entre outros. Segundo Pinho (2007), em Roma foram construídas as mais antigas pontes de pedra utilizando o método de arcos aprendida com os etruscos. A história conta, ainda que, as primeiras pontes surgiram após a revolução industrial e possuíam estruturas simples construídas por madeira e pedras. 
O crescimento econômico e as necessidades humanas impulsionaram um avanço tecnológico na construção civil, proporcionando um olhar mais específico principalmente em obras de grandes portes, foi então que começaram a aparecer técnicas que transmitissem a população uma confiança em transitar por novos caminhos. Com o início do século XX, começaram a surgir pontes de concreto armado, formadas por tabuleiros em concreto armado e com a estrutura de sustentação construídas em arcos tri articulados de concreto simples, em meados de 1912 que veio a ser utilizado o concreto armado na mesoestrutura no momento em que, as pontes constituídas por vigas e pórtico, com vão de até $30 \mathrm{~cm}$, começaram a ser construída.

Mesmo a ponte surgindo desde então para facilitar a vida humana Júnior e Lopes (2016), citam os fatores negativos quanto a construção de obras desse porte, que causam grandes impactos ambientais com: permanente modificação da topologia do ambiente, o desequilíbrio do ecossistema devido a fortes barulhos, a alteração local da atmosfera, entre outros fatores.

\subsection{Manifestações patológicas das Pontes}

O estudo das manifestações patológicas pode ser visto como uma nova área no campo da engenharia das construções que se ocupa a estudar a origens, formas de manifestações, consequência e mecanismo de ocorrência de tais falhas, levando assim a classificação desses problemas em dois: patologias simples, as que admitem padronização, que requer menos cuidado no tratamento e patologias complexas que requer uma análise mais padronizada com um maior aprofundamento. (SOUZA; RIPPER, 2009).

Segundo Helene (1992, p. 19) "Patologia pode ser entendida como sendo a parte da Engenharia que estuda os sintomas, os mecanismos, as causas e as origens dos defeitos das construções civis, ou seja, é o estudo das partes que compõem o diagnóstico do problema. " E manifestação patológicas são exatamente anomalias que surgem em estrutura devido a vários motivos, como a exposição a fatores naturais e temporais.

Helene (1992), é mencionado que junto as manifestações patológicas ocorridas existem uma terapia, isto é um mecanismo para solucionar esses problemas, para que as obras ou parte delas não deixem de apresentar a eficiência préestabelecida no ato da construção.

Já de acordo com o manual do DNIT IPR 744 (2010), as manifestações patológicas mais frequentes nas pontes de concreto armado são fissuras, desgaste superficial, pipocamento, manchas, ninhos ou falhas de concretagem, desagregação, corrosão, carbonização e etc. A seguir, serão mostradas as principais patologias, explicando suas causas e consequências.

\subsubsection{Fissuras}

Segundo Curcio (2008), as fissuras, são o tipo mais comum de manifestações patológicas em estruturas, e denominamse pequenas fendas que surgem nas estruturas de concreto, onde são inevitáveis até mesmo as normas e regulamentos das construções. A mesma diminui a durabilidade do concreto, modifica as características estruturais da obra e sua formação está diretamente ligado a situações externas e internas.

Segundo a norma de impermeabilização (NBR 9575:2003) as fissuras podem ser classificadas por suas dimensões, sua classificação influencia quanto aos devidos cuidados que devem ser tomados para cada caso especificamente de recuperação da estrutura. No quadro a seguir, são apresentadas as dimensões das fissuras.

Tabela 1 - Relação dos tipos de aberturas direcionadas ao seu dimensionamento. Adaptado NBR 9575:2003

\begin{tabular}{c|c}
\hline TIPOS DE ABERTURA & DIMENSÕES $(\mathrm{mm})$ \\
\hline Microfissuras & Menor que 0,05 \\
\hline Fisuras & Até 0,5 \\
\hline Trincas & 0,5 a 1,0 \\
\hline
\end{tabular}

A fissura pode ter origem em fases diferentes da edificação, no concreto endurecido, pode ser originada por retração do concreto, por secagem, por movimentação térmica precoce ou por corrosão das armaduras. Após um período de tempo 
curto da fase de concretagem pode ocorrer a retração do material, seguido da perda de sua umidade, fazendo surgir fissuras, essas se localizam perpendicularmente a estrutura. Após um período de tempo longo (várias messes ou até mesmo anos) após o termino da construção, pode acontecer o aumento de volume das armaduras decorrente da corrosão, fazendo surgir fissuras ao longo de toda a estrutura armada (DNIT IPR 744, 2010), como mostra a Figura1:

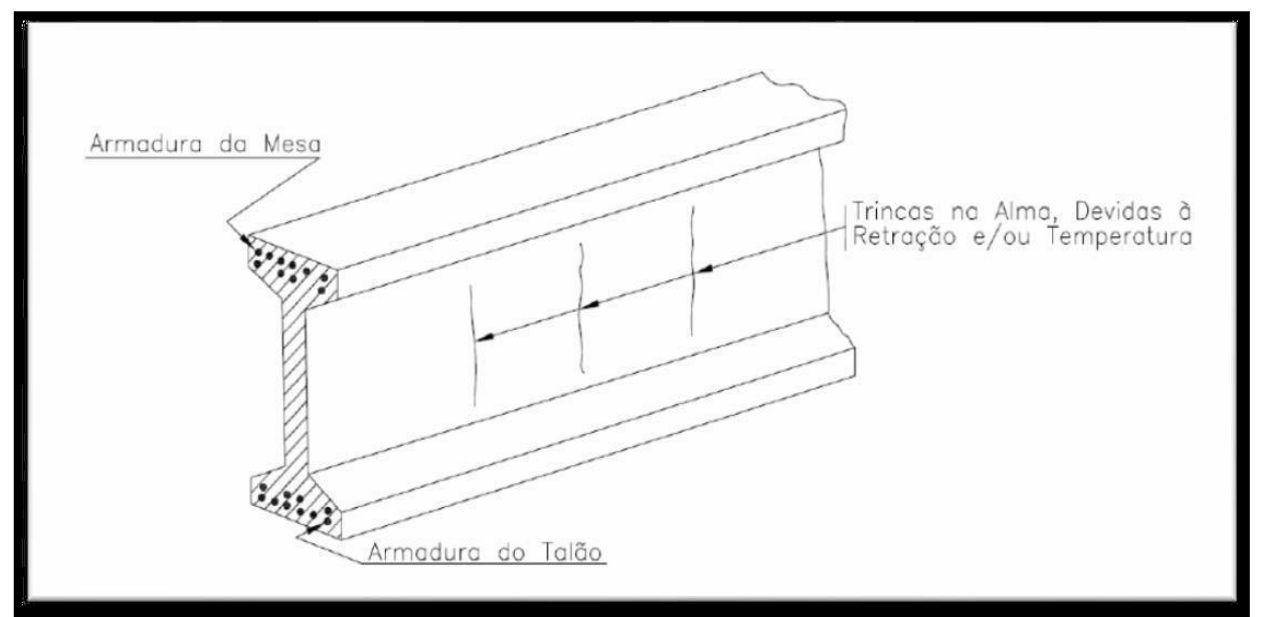

Figura 1: Fissuras devido à retração do concreto. Dnit ipr 744, 2010

\subsubsection{Desgaste superficial}

Segundo o manual do DNIT IPR 744 (2010), este processo se dá pela perda de massa em uma superfície de concreto devida a fatores agravantes como: à abrasão, à erosão e à cavitação. Este acontecimento se dá devido a argamassa não possuir resistência ao atrito, acarretando assim sua perda continua.

\subsubsection{Pipocamento}

Já o pipocamento de acordo com o mesmo manual é uma manifestação patológica que se dá quando ocorre a ruptura e separação do material, no caso do concreto armado, superficial da estrutura, que resulta em buracos que variam de $10 \mathrm{~mm}$ a $50 \mathrm{~mm}$.

\subsubsection{Manchas}

As manchas por sua vez são descoloração que surgem quando ocorre a penetração de substâncias. Trata-se de substâncias irregulares ou compactos de pasta de cimento praticamente sem poros (DNIT IPR 744, 2010).

\subsubsection{Ninhos}

Os ninhos de concretagem também conhecido por falha de concretagem, são vazios que vão sendo deixados na massa de concreto no processo de construção, devido a mal execução ou a dificuldade que o concreto possui em penetrar nas formas durante o processo de lançamento. Acontece quando a argamassa não preenche todos os espaços entre as barras da armadura (DNIT IPR 744, 2010).

\subsubsection{Desagregação}

O manual define desagregação como sendo um fenômeno que se inicia na superfície dos elementos de concreto com uma mudança de coloração e indica a existência de ataque químico, é basicamente quando ocorre a separação entre o cimento e os agregados livres ali depositados.

\subsubsection{Corrosão}

A corrosão por carbonatação, normalmente, é um mecanismo que ocorre e provoca a desagregação, rachaduras ou lascamento da construção em estudo, por meio da seguinte reação química: 


$$
\mathrm{CO} 2 \mathrm{Ca}(\mathrm{OH}) 2-\mathrm{H} 2 \mathrm{O}, \mathrm{NaOH}->\mathrm{CaCO} 3+\mathrm{H} 2 \mathrm{O}
$$

Essa reação química é oriunda da reação de carbanatação, que se produz em soluções aquosas através de reações intermediarias. No concreto existe compostos alcalinos presentes nas soluções dos poros $(\mathrm{NaOH}, \mathrm{KOH})$ que podem vir a reagir quando em contato com o dióxido de carbono que se faz presente na atmosfera. (BETOLINI, 2014)

Segundo esse mesmo autor o concreto em seu estado íntegro apresenta em sua armadura uma película com espessura $\leq$ $10 \mathrm{~mm}$ formada por substancias como óxidos de ferro e hidróxido de cálcio, a carbonatação por sua vez eleva o $\mathrm{Ph}$ dessas soluções existentes nos poros a valores consideravelmente próximos a neutralização fazendo com que o aço perca essa proteção ocasionando a corrosão.

\subsubsection{Carbonização}

A carbonização, também conhecida por carbonatação ou neutralização, é um termo utilizado para descrever o efeito do dióxido de carbono, da atmosfera usualmente no sistema de concreto armado e se dá a partir de um processo químico baseado na conversão dos íons de cálcio do concreto endurecido em carbonato de cálcio, pela reação com o dióxido de carbono presente na atmosfera (DNIT IPR 744, 2010).

Segundo Neville (2016), esse processo em si não causa a danificação do concreto aramado, mas causa algumas consequências entre elas pode-se citar a retratação por carbonatação.

\subsubsection{Eflorescência}

Eflorescências do ponto de vista do autor Neville (2016), é a lixiviação dos compostos de calcário, que podem formar poros na superfície do concreto armado e surgem pelo uso inadequado de agregados procedentes de regiões marinhas que não recebem uma limpeza adequada antes do uso. Fora o fenômeno da lixiviação, este fenômeno tem importância apenas na parte estética da estrutura.

Agora conforme o DNIT IPR 744, 2010 a eflorescência surge do depósito de sais brancos sobre a superfície do concreto, ou seja, quando uma solução contendo sais evapora com a água e os sais se precipitam esses sais em contato com o ar se solidificam, causando depósitos que ficam aparentes na estrutura.

\subsubsection{Desplacamento do concreto}

De acordo com o significado do nome desplacamentodo concreto consiste no movimento provocado pelo desprendimento de fragmentos ou placas de concreto, ao longo da estrutura de concreto armado. (NEVILLE, 2016)

\section{MATERIAIS E MÉTODOS}

\subsection{Local da pesquisa}

O trabalho foi realizado na Ponte Piquet Carneiro localizada na entrada do município de Icó no Estado do Ceará, sobre o Rio Salgado, na rodovia federal BR - 404, que liga a cidade de Icó-CE a Piripiri-PI, a mesma conta com três pares de arcos parabólicos tri articulados de $40 \mathrm{~m}$ de corda e $8,30 \mathrm{~m}$ de flecha, largura igual a $0,50 \mathrm{~m}$, com uma extensão total de $150 \mathrm{~m}$ e uma largura de $8,90 \mathrm{~m}$. Na Figura 2 ilustra-se a localização da ponte 


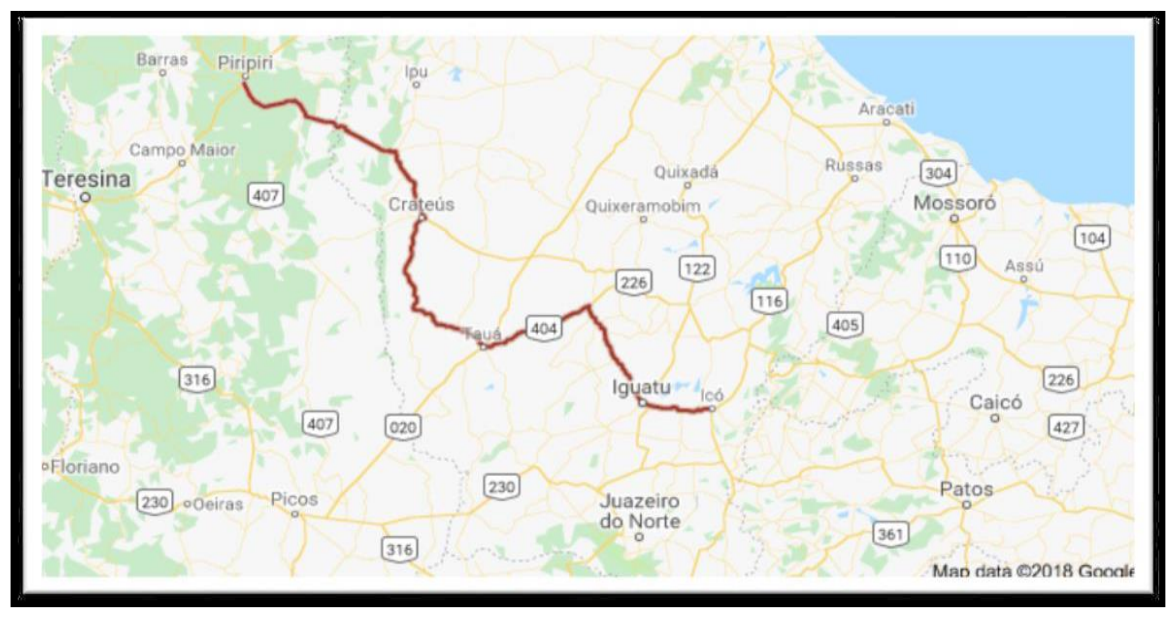

Figura 2: Localização da BR - 404. Google (2018)

\subsection{Levantamento das manifestações patológicas}

O levantamento das manifestações patológicas foi realizado através de visitas in loco e coleta de imagens com auxílio de equipamento fotográfico.

\section{RESULTADOS E DISCUSSÃO}

Com auxílio dos registros fotográficos foi realizado o levantamento das condições gerais da ponte Piquet Carneiro e com as descrições técnicas pode-se observar a presença das seguintes manifestações ao longo de toda a estrutura: fissuras, trincas, manchas, corrosão das armaduras, desagregação e/ou segregação do concreto e eflorescência. Como a análise realizada foi apenas visual, foi possível relatar apenas possíveis causas da ocorrência das manifestações.

\subsection{Manifestações patológicas presentes na superestrutura}

Na superestrutura as manifestações patológicas identificadas foram do tipo fissuras, trincas e manchas.

Nos guarda corpos da ponte foi possível perceber em alguns pontos à desagregação e a corrosão das armaduras, como pode se perceber na Figura 2 em que (a) pode-se observar as manchas e corrosão das armaduras e em (b) está mostrando a desagregação e algumas fissuras leves.

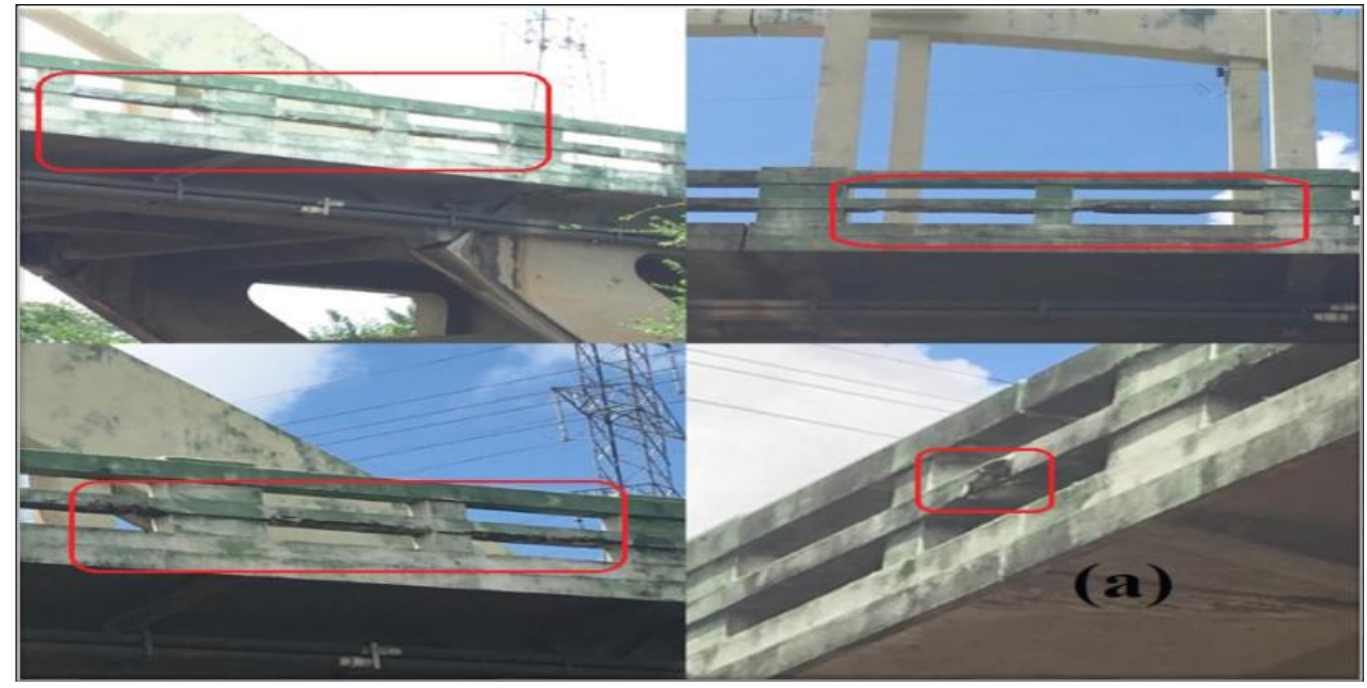

Figura 3: Detalhe dos guarda corpos deteriorados. Acervo do autor (2019) 
Os surgimentos dessas manifestações patológicas podem estar relacionados com inúmeros fatores como condições ambientais e climática, impacto de veículos, a desagregação devido a oxidação ou dilatação das armaduras, influências mecânicas, excesso de vibração com o trânsito diário dos automóveis, entre outros.

Essa ponte é uma estrutura antiga que está submetida a diversas influências, não se tem dados contabilizados da quantidade de acidentes ocorridos no trecho da ponte, porem sabe-se que foram muitos devido a isso alguns guarda corpos e pilares podem ter sofrido colisões diretas provocando a quebra do concreto. A oxidação na armadura e a desagregação nesse caso podem ter duas causas: a falta de manutenção e essas colisões.

Os guarda corpos, não possuem uma função estrutural importante, porém os mesmos estão submetidos as mesmas condições climáticas e ambientais que a estrutura como um todo, dessa forma faz-se necessário um olhar mais especifico para as manifestações patológicas detectadas, pois o tratamento destas é definitivo quanto a durabilidade desses elementos estruturais.

Os pilares dos arcos de maneira geral encontram-se em bom estado apresentando apenas leves fissuras e manchas, todos com as manifestações patológicas iguais.

As fissuras podem ter surgido pela a exposição da estrutura a fenômenos naturais, que favorecem o desgaste do concreto, como a chuvas, isolações ao longo dos anos, na nossa região a maior parte do ano encontra-se em período de seca e o excesso de água também é prejudicial. As manchas ocorrem principalmente pelo excesso de água infiltrada na estrutura, as fissuras podem ser a entrada para esse agente, acarretando a formação de manchas. Pode-se verificar na Figura 3 a presença dessas manifestações em um dos pilares.

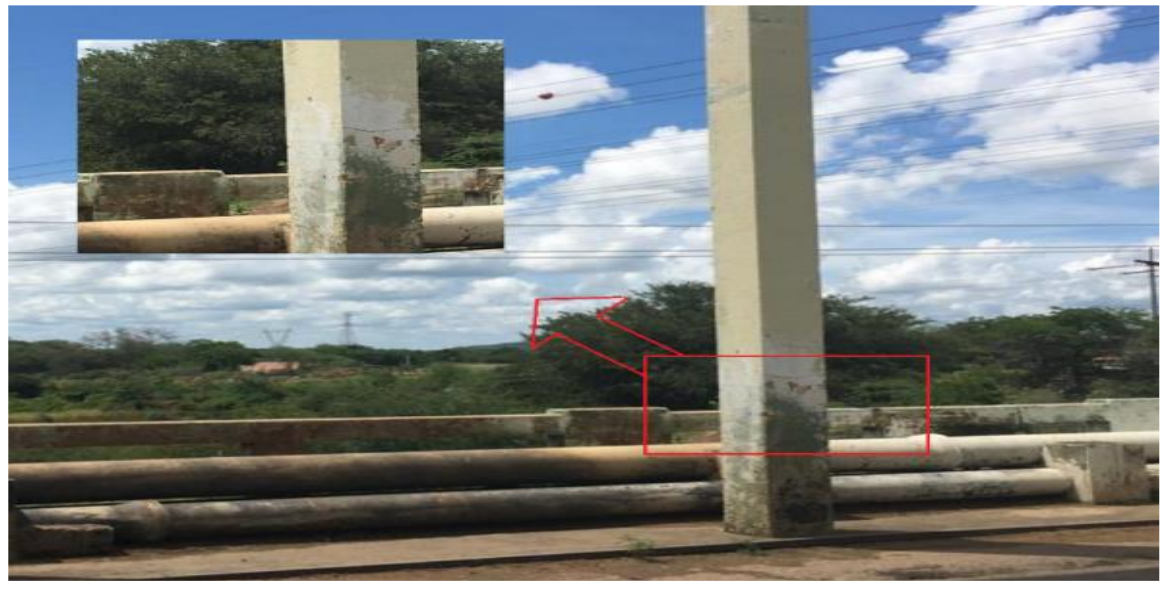

Figura 3: Detalhe dos pilares. Acervo do autor (2019)

Observa-se também na Figura 3, uma tubulação que não existia no projeto inicial, provocando na estrutura um excesso de peso que não foi previsto e provavelmente pode ter provocado algumas manifestações patológicas existentes nesse lado da ponte como fissuras, rachaduras e até desplacamento. A pista de rolamento da ponte apresenta algumas irregularidades, como as mostradas na Figura 3, que são manifestações patológicas do tipo fissuras e rachaduras, em relação ao longo tempo sem recapeamento asfáltico a pista encontra-se em um estado satisfatório.

Essas rachaduras podem ter ocorrido porque a estrutura foi impedida de se movimentar, quando submetidas a variação de temperatura, ou por está submetida diariamente a esforços moveis de fluxo dos automóveis.

A superestrutura da ponte Piquet Carneiro é formada por quatro juntas de dilatação transversais localizada nas extremidades e divisão dos três vãos que à compõe, preenchidas por asfalto. Observa-se que ambas apresentam apenas um desgaste natural, que foi gerada pelo longo tempo que a mesma não passa por manutenções. Como está ilustrado na Figura 4. 


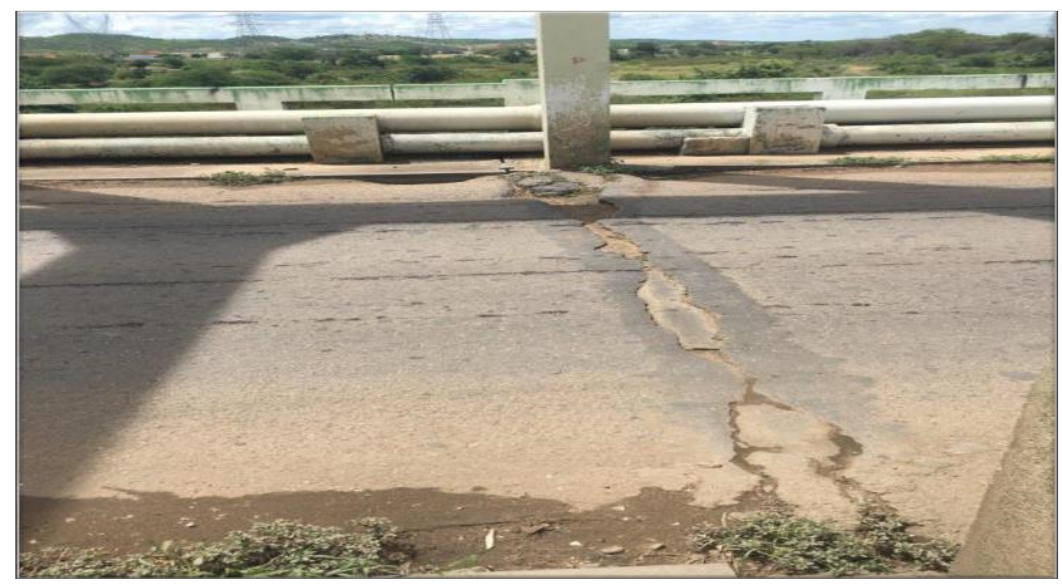

Figura 4: Detalhe das juntas de dilatação. Acervo do autor (2019)

Ainda na superestrutura pode-se verificar a presença de pingadeira (Figura 5), revestida de um material do tipo metálico, esse material apresentam um desgaste na sua superfície, oxidação, essa manifestação, pode ter surgido pelo acumulo de água local, ou basicamente por falta de manutenção. Esse problema pode acarretar outras manifestações patológicas que ao longo tempo poderão comprometer a laje.

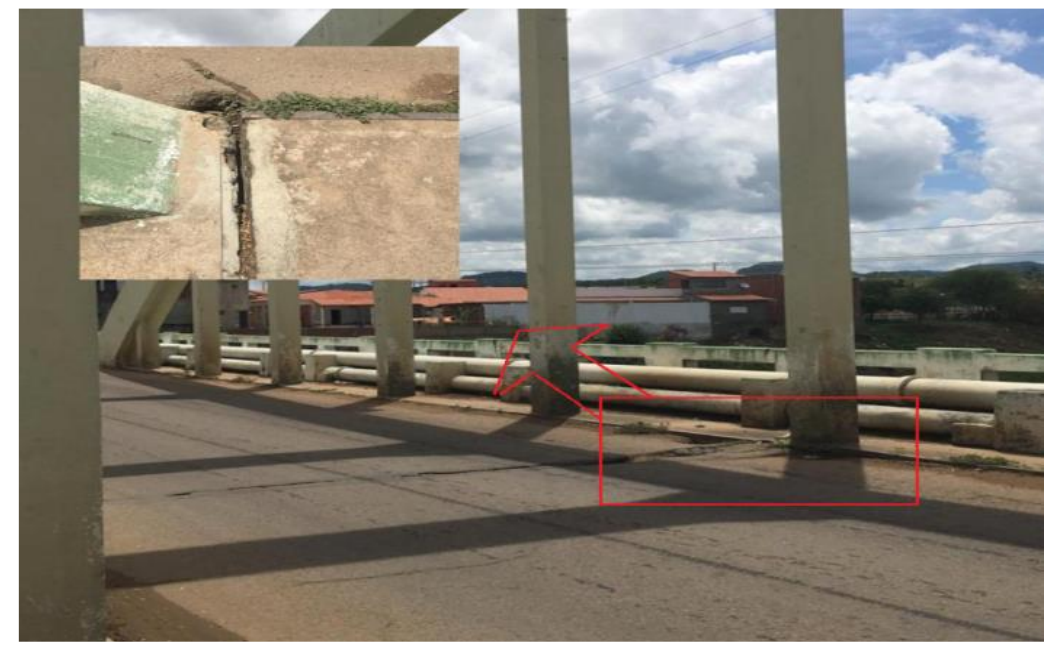

Figura 5: Detalhes da pingadeira. Acervo do autor (2019)

A maioria das pontes são construídas sobre um percurso de água, a ponte em estudo encontra-se sobre o Rio Salgado e este passou por períodos de secas e cheias, nesse período de cheia o nível da água consegue alcançar o tabuleiro. Iniciando do princípio, que para haver corrosão precisa principalmente da presença e/ou da infiltração de água e do oxigênio, podemos supor que essa manifestação surgiu por esse motivo ou pela maneira que a água evaporou e se infiltrou na estrutura, assim como a maneira a água escoa das pingadeiras, que se encontram desgastadas.

Pode-se observar a exposição da armadura em alguns pontos das vigas longitudinais e das vigas transversais. Se tornando assim necessário a realização de reparos uma vez que o fato das armaduras estarem expostas compromete a estrutura, pois a corrosão reduz a resistência a flexão da viga. Na Figura 6 está destacado a oxidação (exposição das armaduras) presentes na estrutura. 


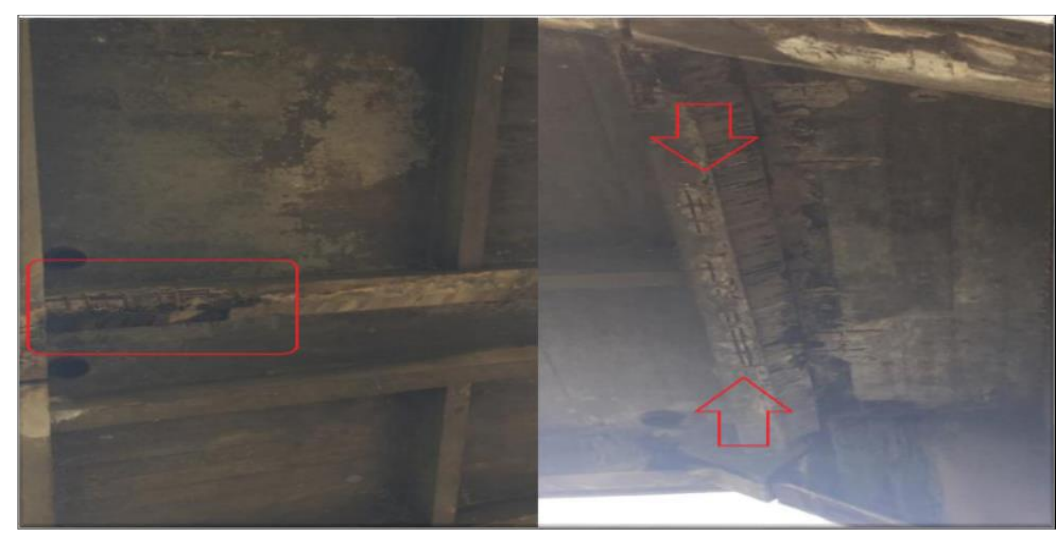

Figura 6: Exposição da armadura presente na superestrutura. Acervo do autor (2019)

Ainda na superestrutura podemos notar o processo de manchas e eflorescência, que podem ter ocorrido pela infiltração de água. Essas manifestações patológicas estão presentes em vários locais da estrutura.

\subsection{Manifestações patológicas presentes na mesoestrutura}

A mesoestrutura de uma ponte é, em geral constituída por pilares do tipo parede maciça de concreto, aparelhos de apoios e encontro. Os pilares da Ponte Piquet Carneiro apresentam algumas manifestações patológicas como desplacamento do concreto, corrosão das armaduras e eflorescência. A Figura 7 ilustra a corrosão das armaduras nos pilares. Essas podem comprometer a estrutura, quando levado em consideração que os pilares são responsáveis por receber os esforços da superestrutura e transmiti-los para infraestrutura.

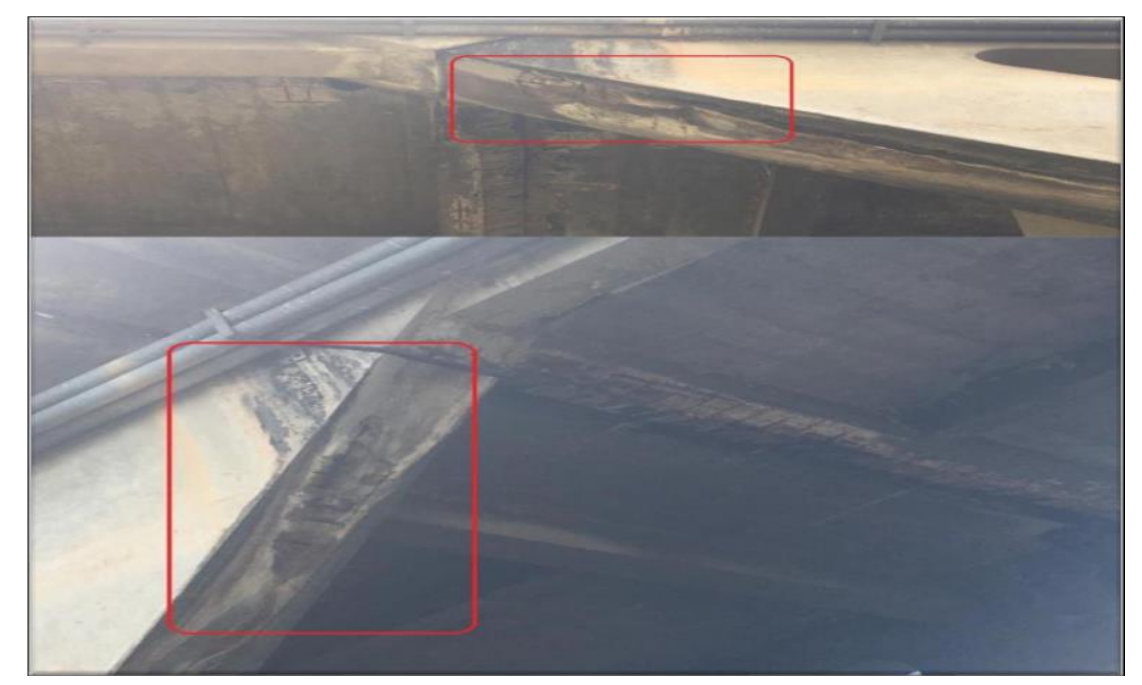

Figura 7: Corrosão das armaduras presente nos pilares. Acervo do autor (2019)

Eflorescência são depósitos de sais na superfície do concreto que formam manchas brancas, está ligada à infiltração das águas através das trincas e fissuras presente na ponte assim como pelas juntas de dilatação do tabuleiro, e está por si só é um problema mais estético.

Em alguns pilares foi detectada a presença de eflorescência e manchas, como foi destacado na Figura 8. 

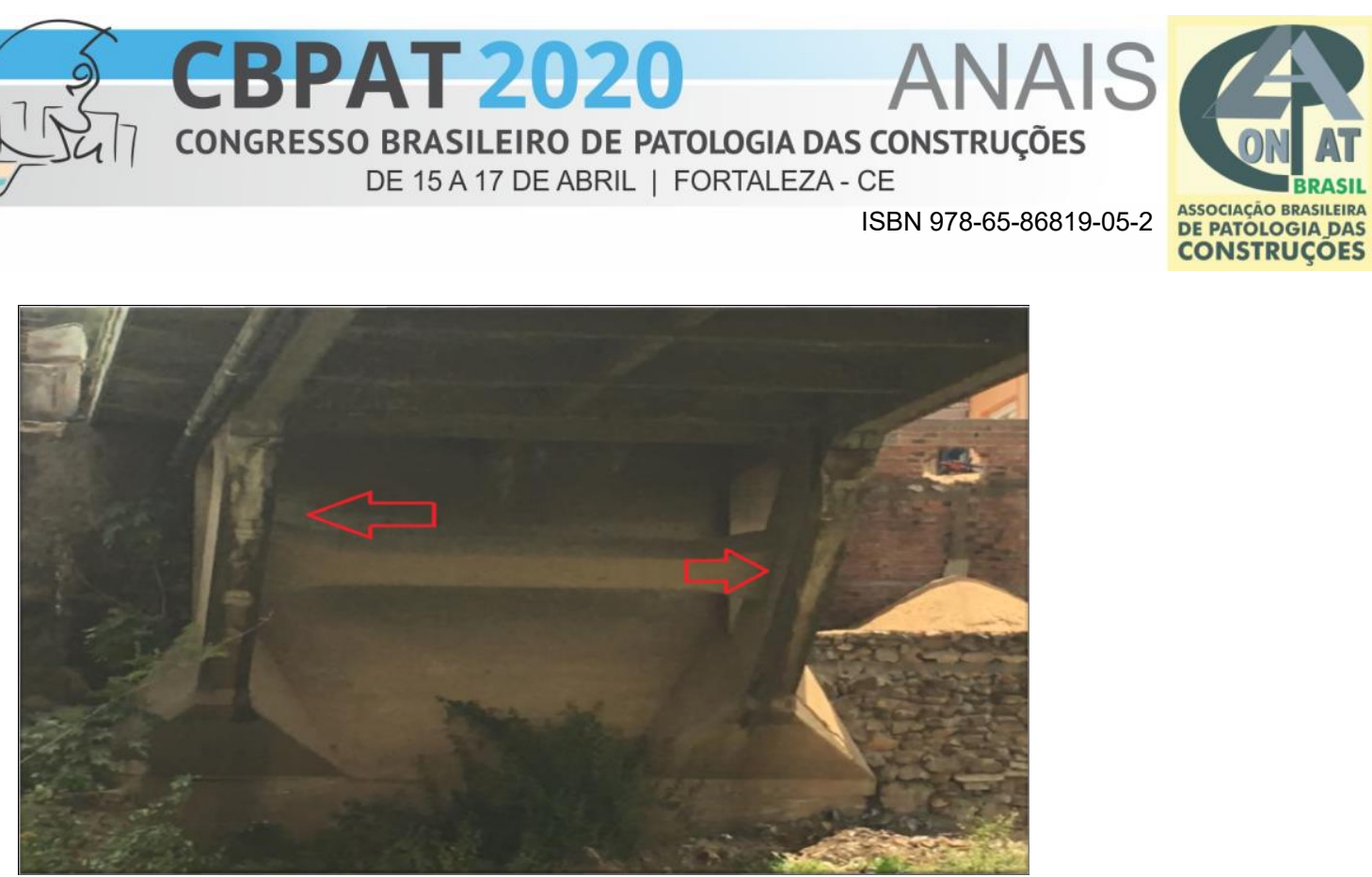

Figura 8: Efeito da eflorescência e das manchas no pilar. Acervo do autor (2019)

\subsection{Manifestações patológicas presentes na infraestrutura}

A infraestrutura é constituída por estacas pré-moldadas de concreto, coroadas por blocos de concreto armado. Pode-se observar que essas estacas estão aparentemente conservadas e não apresentam manifestações patológicas visíveis como ilutas na Figura 9. Para a estrutura é um ponto positivo, pois as estacas são de difícil acesso para uma manutenção e ainda são responsáveis por suportar as cargas recebidas da estrutura e as cargas móveis.

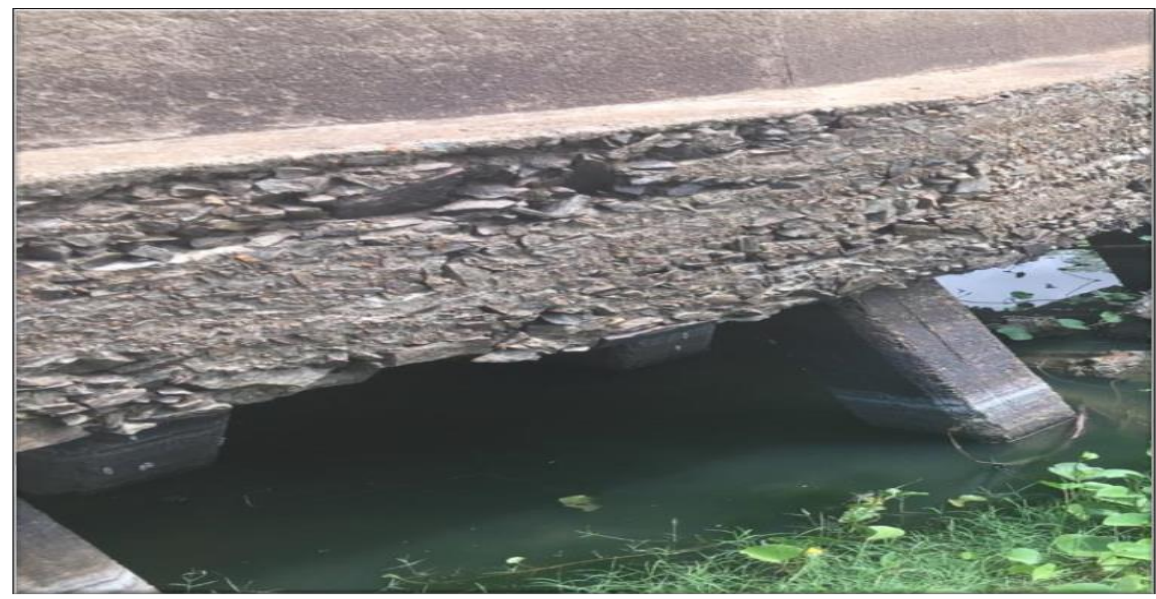

Figura 9: Estacas da infraestrutura. Acervo do autor (2019)

\section{CONCLUSÕES}

Este trabalho teve como objetivo principal realizar um levantamento das condições gerais da Ponte Piquet. Diante do exposto e das condições de realização do trabalho foi possível concluir que:

- A vistoria no local propiciou a identificação das manifestações patológicas presente na Ponte como fissuras, rachaduras, eflorescência, manchas, desagregação, desplacamento e corrosão das armaduras. 
- A superestrutura é a região estrutural que apresenta a maior quantidade de manifestações patológicas, a instalação da tubulação no lado direito da ponte pode ser uma das causas desses problemas, a aparição de grandes rachaduras na pista de rolamento, possivelmente denunciam grandes movimentações difíceis de ser absorvidas.

- As juntas de dilatações apresentaram um desgaste natural, com pouca vedação, e nas pingadeiras uma corrosão na estrutura, ambos favorecem a infiltração das águas acarretando a deterioração do tabuleiro, que apresentou na parte inferior corrosão nas armaduras e a presença de manchas e eflorescência.

- Na mesoestrutura foi possível observar o desplacamento no concreto dos pilares, algumas manchas, eflorescência e corrosão nas armaduras.

- A infraestrutura não apresentou manifestações patológicas consideráveis.

- As manifestações patológicas mais preocupantes presentes na estrutura foram a exposição das armaduras na parte externa da superestrutura e o desplacamento do concreto nos pilares da mesoestrutura.

- A grande maioria das manifestações patológicas encontradas na ponte poderiam ser evitadas com pequenos reparos e manutenção, porém é notório que não existe uma política de manutenção periódica para essas obras de artes especiais.

Com o estudo pode-se observar que a Ponte Piquet Carneiro se encontra deteriorada, porem com um resultado satisfatório levando em consideração a inexistência ou falta total de manutenção em todo seu tempo de uso. No entanto pode-se considerar que para manter a sua integridade física, aumentar sua vida útil e atender aos requisitos para os quais a mesma foi projetada, seria necessários reparos em elementos estruturais importantes como os pilares, a parte interna do tabuleiro e os guarda corpos.

\section{REFERÊNCIAS}

ABNT NBR 9575: Seleção e projeto de impermeabilização. Rio de Janeiro, 2003.

BERTOLINI, Luca. Materiais de construção: patologia, reabilitação, prevenção. São Paulo: Oficina de Texto, 2014. $414 \mathrm{p}$.

CURCIO, Ronald Cristhian de Lima. PONTES RODOVIÁRIAS: Levantamento das principais patologias estruturais. 2008. 56 f. TCC (Graduação) - Curso de Engenharia Civil, Universidade São Francisco, Itatiba, 2008.

DNIT. (2010). Manual de Recuperação de Pontes e Viadutos Rodoviários. Departamento Nacional de Infraestrutura de Transportes. Diretoria Executiva, Rio de Janeiro.

HELENE, Paulo R. L. Manual para Reparo, Reforço e Proteção de Estruturas de Concreto. 2a ed. São Paulo: Pini, 1992

LEONHARDT, Fritz. Construção de concreto: princípios básicos da construção de pontes de concreto. Rio de Janeiro: Interciência, 2013. 241 p. 6 v.

LOPES JÚNIOR, Marcelo Sérgio Couteiro; LOPES, Marcileia Couteiro. Impactos da construção da Ponte sobre o Rio negro, no cotidiano dos produtores rurais da comunidade nova esperança - Iranduba/AM. In: ASSOCIAÇÃO NACIONAL DE PÓS-GRADUAÇÃO E PESQUISA EM AMBIENTE E SOCIEDADE MANAUS, 1., 2016, Amazônia. Anais... . Amazônia, 2016. p. 1 - 27.

MARCHETTI, Osvaldemar. Pontes de concreto armado. São Paulo: Blucher, 2017. 237 p.

NEVILLE, A.M . Propriedades do concreto. 5. ed. Porto Alegre: Bookman, 2016. 888 p.

PINHO, Fernando Ottoboni, BELLEI, Ildony Hélio, Pontes e viadutos em vigas mistas, $1^{\text {a }}$ ed. Rio de Janeiro, IBS/CBCA, 2007 


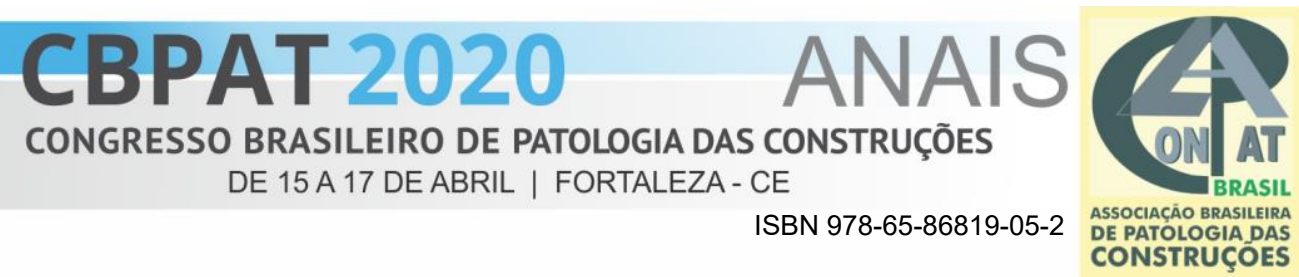

SANTOS, Alfredo Gomes Francisco da Siva; SOUZA, Anderson Oliveira de; FARIAS, Manoel Leandro Araújo e. Levantamento das manifestações patológicas de uma ponte de concreto armado junto as suas possíveis técnicas de recuperação. In: CONFÊRENCIA NACIONAL DE PATOLOGIAS E RECUPERAÇÕES DE ESTRUTURAS, 1., 2017, Recife. Anais... . Recife: Conpar, 2017. p. 1 - 10.

VITÓRIO, J. A. P. Vistorias, Conservação e Gestão de Pontes e Viadutos de Concreto. Anais do $48^{\circ}$ Congresso Brasileiro do Concreto, 2006. 